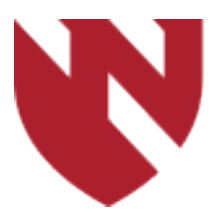

December 2019

\title{
Advanced Pancreatic Cancer: A Meta-Analysis of Clinical Trials over Thirty Years
}

\author{
Bradley R. Hall \\ University of Nebraska Medical Center \\ Jennifer A. Leinicke \\ University of Nebraska Medical Center \\ Priscila R. Armijo \\ University of Nebraska Medical Center \\ Lynette M. Smith \\ University of Nebraska Medical Center \\ Sean J. Langenfeld \\ University of Nebraska Medical Center
}

See next page for additional authors

Tell us how you used this information in this short survey.

Follow this and additional works at: https://digitalcommons.unmc.edu/gmerj

Part of the Higher Education Commons, and the Medicine and Health Sciences Commons

\section{Recommended Citation}

Hall, B. R., Leinicke, J. A., Armijo, P. R., Smith, L. M., Langenfeld, S. J., , Oleynikov, D. Advanced Pancreatic Cancer: A Meta-Analysis of Clinical Trials over Thirty Years. Graduate Medical Education Research Journal. 2019 Dec 13; 1(1).

https://digitalcommons.unmc.edu/gmerj/vol1/iss1/43

This Conference Proceeding is brought to you for free and open access by DigitalCommons@UNMC. It has been accepted for inclusion in Graduate Medical Education Research Journal by an authorized editor of DigitalCommons@UNMC.For more information, please contact digitalcommons@unmc.edu. 


\section{Advanced Pancreatic Cancer: A Meta-Analysis of Clinical Trials over Thirty Years}

Creative Commons License

(c) (i)@(ङ)

This work is licensed under a Creative Commons Attribution-Noncommercial-No Derivative Works 4.0 License.

\section{Authors}

Bradley R. Hall, Jennifer A. Leinicke, Priscila R. Armijo, Lynette M. Smith, Sean J. Langenfeld, and Dmitry Oleynikov 
to be weaned off hemodialysis along with the benefit of concurrent amelioration of renovascular hypertension.

Conclusion: For select patients with RAO there can benefits, such as achieving dialysis independence and stabilization of renovascular hypertension, by attaining revascularization of the renal arteries despite prolonged time of ischemia.

https://doi.org/10.32873/unmc.dc.gmerj.1.1.041

\section{No Survival Advantage Exists for Patients Undergoing Loop lleostomy for Clostridium difficile Colitis}

Bradley R. Hall, Andrew Cannon, Pranita Atri, Christopher S. Wichman, Lynette M. Smith, Apar K. Ganti, Chandrakanth Are, Aaron R. Sasson, Sushil Kumar, Surinder K. Batra

\section{Mentor: Dmitry Oleynikov \\ Program: General Surgery}

Background \& Objectives: Loop ileostomy (LI) remains an unproved alternative to total abdominal colectomy (TAC) for patients with Clostridium difficile infection (CDI). We aim to compare outcomes between loop ileostomy and total abdominal colectomy for Clostridium difficile infection using a national database.

Methods: The 2011-2016 ACS-NSQIP database was queried for patients who underwent LI or TAC for CDI. Patients with high outlying age, LOS, and operative time were excluded. Statistics were performed using IBM SPSS and NCSS PASS 11.

Results: Of 457 patients identified, 47 underwent LI. Predicted morbidity was higher in the TAC cohort $(62 \%$ vs. $37 \%, \mathrm{p}<0.001)$. Patients in the LI cohort experienced fewer complications $(72 \%$ vs. $87 \%, \mathrm{p}=0.021)$; however, mortality did not differ between LI (36\%) and TAC (31\%) cohorts. Blood transfusions were more than twice as frequent in the TAC cohort ( $54 \%$ vs. $19 \%$, $\mathrm{p}<0.001)$. Four patients in the LI cohort required reoperation; however, none required colectomy.

Conclusions: Compared to TAC, LI does not improve survival for patients who require surgical intervention for CDI.

https://doi.org/10.32873/unmc.dc.gmerj.1.1.042

\section{Advanced Pancreatic Cancer: A Meta-Analysis of Clinical Trials over Thirty Years Bradley R. Hall, Jennifer A. Leinicke, Priscila R. Armijo, Lynette M Smith, Sean J. Langenfeld, Dmitry Oleynikov}

Mentor: Surinder Batra

Program: General Surgery

Background \& Objectives: In contrast to other cancers, survival rates for pancreatic ductal adenocarcinoma (PDAC) have improved but minimally over the past thirty years. The aim of this study was to perform a meta-analysis of clinical trials published since 1986 to determine trends in median overall survival in primarily metastatic PDAC.

Methods: All Phase 2-4 clinical trials published during or after 1986 investigating first-line systemic chemotherapy in metastatic PDAC were included in the meta-analysis. Publications obtained through PubMed and
www.ClinicalTrials.gov were cross-referenced to identify additional trials. Trials enrolling fewer than $50 \%$ of study participants with metastatic disease were excluded.

Results: Of 19,488 patients enrolled in 151 clinical trials, $84 \%$ had metastatic disease and $16 \%$ had locally advanced pancreatic cancer. In clinical trials published from 1986 to 2016 , the weighted median overall survival (wMOS) increased by 3.0 months. The median wMOS was higher in combination therapy (7.31 months, IQR 5.4 to 8.5) compared to non-gemcitabine, single-agent therapy (4.76 months, IQR 3.5 to 6.0), gemcitabine monotherapy (6.48 months, IQR
5.9 to 7.2 ), and gemcitabine plus single-agent therapy (7.09 months, IQR 6.3 to 8.2 ). Of all regimens used in more than one study arm, FOLFIRINOX had the highest wMOS (10.9 months).

Conclusions: Regardless of treatment regimen, survival rates in PDAC have minimally improved over time. Of drugs used in two or more study arms, only FOLFIRINOX has a wMOS greater than ten months. Emphasis should, therefore, be placed on identification of novel targets that promote early diagnosis and intervention.

https://doi.org/10.32873/unmc.dc.gmerj.1.1.043

\section{National Trends in Survival for Pancreatic Adenocarcinoma Based on Location of the Primary Lesion Gautam K. Malhotra, Lynette M. Smith, Quan P. Ly, Aaron R. Sasson, Chandrakanth Are}

Mentor: Chandrakanth Are

Program: General Surgery

Background: The management and prognosis of pancreatic adenocarcinoma varies depending on the location of the primary lesion within the pancreas. There is a paucity of data on survival trends in pancreatic adenocarcinoma based on the location. The aim of this study was to analyze the national trends in survival for patients with pancreatic adenocarcinoma based on the location of the primary lesion.

Methods: The Surveillance, Epidemiology, and End Results (SEER) database (SEER 17, 1973-2007) was used to identify patients with pancreatic cancer located in the head (C25.0), body (C25.1), or tail (C25.2). SEER*Stat
6.6.2 was used to calculate 5-year survival data. To stabilize rates, we used 5-year cohorts when calculating trends.

Results: A total of 89,733 patients were included in the study. The overall 5-year survival, inclusive of all locations and treatment approaches was is $5.4 \%(95 \% \mathrm{CI}$ 5.2-5.6\%). For lesions in the head, body and tail the overall 5-year survival, inclusive of 